\title{
A criança com encefalopatia crônica não progressiva: impacto da doença para 0 cuidador
}

\section{The child with non-progressive chronic encephalopathy: impact of the disease on the care giver}

\section{El niño con encefalopatía crónica no progresiva: impacto en el cuidado}

\author{
Érika Alves Germano iD \\ Centro Universitário Instituto Superior de Teologia Aplicada - Sobral (CE) - Brasil
}

Edna Pinto Medeiros de Lima iD

Centro Universitário Instituto Superior de Teologia Aplicada - Sobral (CE) - Brasil

Mauro Vinicius Dutra Girão iD

Centro Universitário Instituto Superior de Teologia Aplicada - Sobral (CE) - Brasil

Maria Dandara Alves Ribeiro (iD

Centro Universitário Instituto Superior de Teologia Aplicada - Sobral (CE) - Brasil

Mara Dayanne Alves Ribeiro iD

Centro Universitário Instituto Superior de Teologia Aplicada - Sobral (CE) - Brasil

\section{RESUMO}

Objetivo: Conhecer a percepção do cuidador primário quanto à doença e ao cuidado com a criança com encefalopatia crônica não progressiva (ECNP). Métodos: Trata-se de um estudo de campo do tipo descritivo, com abordagem qualitativa, realizado em outubro de 2019 sobre a realidade que envolve o processo de cuidado de pacientes com ECNP. Entrevistaram-se nove cuidadores de pacientes atendidos em uma clínica municipal de fisioterapia de um município de pequeno porte do interior do Ceará, Brasil, por meio de entrevista semiestruturada, posteriormente analisada por meio da análise de conteúdo, emergindo as categorias temáticas: Limitações da criança com ECNP; Reações do cuidador ao diagnóstico da criança com ECNP; Perspectivas futuras da criança com ECNP; Preconceito com a criança portadora de ECNP; A criança portadora de ECNP sobrecarrega a saúde do cuidador. Resultados: Os resultados apontam que o cuidador primário passa por fases críticas, que iniciam com o diagnóstico, perduram durante o processo de cuidado e trazem receios futuros quanto ao prognóstico do quadro clínico, aceitação social, escolarização, mercado de trabalho e morte. Conclusão: Este estudo evidencia a necessidade de apoio dos profissionais de saúde para o tratamento e orientações para o cuidado adequado desse público.

Descritores: Paralisia Cerebral; Cuidadores; Emoções.

\section{ABSTRACT}

Objective: to know the perception of the primary caregiver regarding the disease and care for the child with Chronic Non-Progressive Encephalopathy (ECNP). Methods: It is a descriptive field study, with a qualitative approach, conducted in October 2019 on the reality that involves the care process of patients with NECP. Nine caregivers of patients seen at a municipal physiotherapy clinic in a small town in the interior of Ceará, Brazil, were interviewed through semi-structured interviews, subsequently analyzed through content analysis, emerging the thematic categories: Limitations of the child with ECNP; Caregiver reactions to the child's diagnosis with ECNP; Future perspectives of the child with ECNP; Prejudice against the child with ECNP; The child with ECNP burdens the caregiver's health. Results: The results indicate that the primary caregiver goes through critical phases, which start with the diagnosis, last during the care process, and bring future fears about the clinical condition prognosis, social acceptance, schooling, job market, and death. Conclusion: this study highlights the need for support from health professionals for the treatment and guidelines for adequate care of this public.

Descriptors: Cerebral Palsy; Caregivers; Emotions.

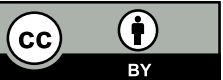




\section{RESUMEN}

Objetivo: Conocer la percepción del cuidador primario sobre la enfermedad y el cuidado del niño con encefalopatía crónica no progresiva (ECNP). Métodos: Se trata de un estudio de campo del tipo descriptivo de abordaje cualitativo realizado en octubre de 2019 sobre la realidad que comprende el proceso del cuidado de pacientes con ECNP. Se ha entrevistado nueve cuidadores de pacientes asistidos en una clínica de fisioterapia de un municipio pequeño del interior de Ceará, Brasil, a través de entrevista semiestructurada que ha sido analizada por el análisis de contenido del cual ha surgido las categorías temáticas a continuación: Limitaciones del niño con ECNP; Reacciones del cuidador sobre el diagnóstico del niño con ECNP; Perspectivas futuras del niño con ECNP; Prejuicio contra el niño portador de ECNP; El niño portador de ECNP sobrecarga la salud del cuidador. Resultados: Los resultados apuntan que el cuidador primario pasa por fases críticas que se inician con el diagnóstico, permanecen durante todo el proceso del cuidado y traen miedos futuros del pronóstico del cuadro clínico, la aceptación social, la escolarización, el mercado de trabajo y la muerte. Conclusión: Ese estudio evidencia la necesidad del apoyo de los profesionales sanitarios para el tratamiento y las orientaciones del cuidado adecuado de ese público.

Descriptores: Parálisis Cerebral; Cuidadores; Emociones.

\section{INTRODUÇÃO}

A paralisia cerebral (PC) ou encefalopatia crônica não progressiva (ECNP) é um conjunto de desordens, em decorrência de distúrbios não progressivos, que limitam diversos fatores da capacidade funcional, entre eles o desenvolvimento motor, a comunicação e a cognição(1).

Tal alteração pode ser resultado de uma lesão no sistema nervoso central (SNC), no período de maturação e desenvolvimento, durante as fases pré-natal, perinatal e pós-natal, tendo como consequência o comprometimento do tônus muscular, da motricidade, deformidades, entre outros, que variam com a idade da criança e a localização da lesão cerebral(2). A criança com ECNP exige bastante cuidado e, após o diagnóstico, a família passa a ter outra realidade, sendo necessária a adaptação da rotina de acordo com a necessidade do novo integrante da família(3).

Mesmo com avanços médicos para diagnósticos e intervenções pré e perinatais, a ECNP ainda é um distúrbio incapacitante do neurodesenvolvimento da criança $^{(4)}$. Nos países desenvolvidos, a prevalência de ECNP varia de 1,5 a 5,9/1.000 nascidos vivos. Estima-se que a incidência nos países em desenvolvimento seja de 7/1.000 nascidos vivos. O número em países em desenvolvimento, como o Brasil, pode ser maior devido às más condições de cuidados pré-natais e ao atendimento primário às gestantes ${ }^{(5)}$.

No levantamento epidemiológico em relação à história gestacional sobre a realização de exames pré-natais pelas mães, a grande maioria foi consultada por profissional especializado entre 6 a 9 consultas pré-natais. Exames pré-natais são importantes, pois a encefalopatia crônica pode ocorrer nas fases pré-natal, perinatal e pós-natal, por inúmeras causas, com infecções, AIDS, uso de entorpecente, tabaco, álcool, desnutrição e traumas ${ }^{(6,7)}$.

Após o diagnóstico de ECNP, na maioria das vezes, quem exerce o papel de cuidador primário é a mãe, que, além das atividades domésticas, tem a sobrecarga do filho, que exige total atenção e dedicação. $O$ cuidador primário é definido como aquele que tem a principal ou total responsabilidade com relação à atenção diária da criança, ou seja, aquele que coloca as necessidades do paciente em primeiro lugar e abdica a sua vida para, assim, realizar esse papel por completo(8).

A atenção com a criança passa a ser redobrada na medida em que ela vai crescendo(9,10). Em alguns casos, o cuidador dificilmente participa de atividades de lazer sem que o filho esteja presente. Dessa forma, o cuidador primário sofre de várias maneiras, além da sobrecarga física, também sofre emocionalmente, pois sentimentos como insegurança, impotência, culpa e desamparo, por familiares e até mesmo por profissionais da saúde, abalam esse cuidador e geram consequências, como renunciar a sua vida pessoal para viver a maior parte do seu tempo em benefício da criança. É nesse aspecto que o ato de cuidar passa a ter algumas repercussões negativas para a vida do cuidador, levando a interferências na saúde em geral ${ }^{(11)}$.

Com o diagnóstico da criança, os cuidadores passam a enfrentar dificuldades na rotina diária no manuseio da criança, na alimentação, no banho ou no vestir. A preocupação do cuidador com a aceitação da sociedade e com o preconceito também são fatores que desencadeiam seu desgaste físico e psíquico ${ }^{(9)}$. A situação financeira da família também é afetada, pois a criança precisará de gastos a mais com a saúde, por exemplo: exames, remédios, profissionais, necessidades básicas, tratamentos e cuidados em geral(12). Existem evidências de que mães de crianças com ECNP apresentam uma maior tendência a desenvolverem ansiedade e depressão quando comparadas às 
mães de crianças sem deficiências. Conflitos familiares também fazem parte da vida dessa cuidadora, gerados pela adaptação que toda a família precisa vivenciar ${ }^{(13,14)}$.

A ECNP é amplamente estudada, e a maioria dos estudos é voltada para a criança diagnosticada com ECNP(5,6), mas entre os problemas causados à criança pela doença estão também as necessidades do próprio indivíduo prestador de cuidados $^{(5)}$. São raras as pesquisas relacionadas aos cuidadores dessas crianças, que precisam também viver dignamente para conseguir realizar seu papel com dignidade ${ }^{(12,15)}$. Dessa forma, essa carência torna a presente pesquisa necessária.

A Portaria n. ${ }^{\circ}$ 2.446, de 11 de novembro de 2014, que redefine a Política Nacional de Promoção da Saúde (PNPS) como um conjunto de estratégias e formas de produzir saúde, de forma individual e coletiva, determina que a integralidade na promoção da saúde passa a ser uma estratégia de produção de saúde ${ }^{(16)}$. Os cuidadores configuram-se aqui como parte da integralidade do cuidado às crianças atingidas por $E C N P^{(4)}$. Diante desse contexto, foi formulada a seguinte pergunta norteadora: como o cuidador primário percebe a doença e o cuidado com sua criança atingida pela encefalopatia crônica não progressiva?

Assim, o objetivo desta pesquisa foi conhecer a percepção do cuidador primário quanto à doença e ao cuidado da criança com encefalopatia crônica não progressiva (ECNP).

\section{MÉTODOS}

A pesquisa caracterizou-se por ser do tipo descritivo, com abordagem qualitativa(17,18) sobre a realidade que envolve o processo de cuidado de pacientes com ECNP. O campo de pesquisa foi a Clínica Municipal de Fisioterapia de um município de pequeno porte do interior do Ceará, Brasil, da qual participaram os cuidadores primários de crianças com ECNP em atendimentos fisioterapêuticos no mês de outubro de 2019. Convidou-se a participar da pesquisa todos os cuidadores que acompanhassem crianças atendidas na clínica com o diagnóstico de ECNP.

Adotou-se como critérios de inclusão: cuidadores primários de criança diagnosticada com ECNP, de ambos os sexos e que sejam maiores de idade. Foram excluídos todos os cuidadores menores de 18 anos, os cuidadores primários que se recusaram a participar da pesquisa ou que não estiveram presentes no período da coleta e os cuidadores secundários, ou seja, que ajudam em nível econômico, do apoio em atividades sociais e de lazer, entre outras ${ }^{(19)}$.

Todos os convidados aceitaram participar do estudo e todos estiveram na clínica acompanhando crianças com ECNP no período analisado. Como se trata de uma pesquisa qualitativa, a amostra foi limitada por saturação de informações ${ }^{(20)}$. Assim, a amostra incluiu nove participantes.

Realizou-se uma entrevista semiestruturada(21), constando de duas etapas: dados de identificação do cuidador primário com as variáveis parentesco com a criança e idade, e com a seguinte questão básica, baseada no objetivo: o que é para você cuidar de sua criança portadora de encefalopatia crônica não progressiva? A entrevista aconteceu em ambiente reservado, no qual se encontravam apenas o pesquisador e o cuidador, enquanto a criança era atendida pelo serviço de fisioterapia da clínica, com duração aproximada de 60 minutos, em um clima amistoso entre entrevistador e entrevistado.

Utilizou-se para a análise dos dados o método de análise de conteúdo, cuja operacionalização aconteceu em três etapas: a pré-análise, a exploração do material e o tratamento dos resultados ${ }^{(22)}$. Ademais, após a análise de conteúdo das entrevistas, surgiram categorias que sumarizam as respostas: Limitações da criança com ECNP; Reações do cuidador ao diagnóstico da criança com ECNP; Perspectivas futuras da criança com ECNP; Preconceito com a criança atingida por ECNP; A criança portadora de ECNP sobrecarrega a saúde do cuidador.

A pesquisa foi submetida ao Comitê de Ética em Pesquisa do Centro Universitário INTA (Uninta), sendo aprovado segundo Parecer $n^{\circ}$ 3.635.099. A participação dos cuidadores foi voluntária, mediante assinatura do Termo de Consentimento Livre e Esclarecido (TCLE). Para manter o anonimato, os nomes dos cuidadores foram substituídos pelas letras "CP", que se referem à expressão "cuidador primário", seguido de numeral arábico na sequência das entrevistas, conferindo o sigilo total aos participantes.

\section{RESULTADOS E DISCUSSÃO}

Participaram do estudo nove cuidadores primários. Todos eram mães, com faixa etária entre 30 a 50 anos de idade, que acompanhavam seus filhos portadores de ECNP durante o atendimento na clínica de fisioterapia. Esse dado é corroborado por outras pesquisas quando afirma que a mulher sempre foi responsável pelo cuidado, seja da casa, seja dos filhos, até mesmo das pessoas enfermas, enquanto o papel do homem, muitas vezes, era trabalhar fora para garantir o provimento financeiro da família( ${ }^{(23)}$. 
A partir das falas analisadas puderam ser destacadas as categorias temáticas, agrupadas por sua similaridade de conteúdo. Foram selecionados trechos das falas dos cuidadores que representavam cada categoria, como se pode observar a seguir.

\section{Limitações da criança com ECNP}

Esta categoria, limitações da criança com ECNP, trata das dificuldades que as crianças apresentam no ponto de vista das mães. O que mais se destacou foram atividades de vida diária e, principalmente, a dificuldade de deambular, como se pode perceber nas falas:

"Uma dificuldade que ele tem é de receber a comidinha na boca com a colher. Ele já tem outras dificuldades... porque ele também não anda, não é?! É, não andar, não botar a colherzinha na boca, só isso, motora, é só isso mesmo." (CP1)

"Ele tem dificuldade de se vestir, não é?! Tem dificuldade de falar... Ele tem dificuldade, às vezes, ao pegar pequenas coisas, ao andar também, não é?! Ele anda, mas é com dificuldade... (risos)." (CP9)

As dificuldades nela? Bem, são todas as coisas, porque ela não anda, depende totalmente de mim, os movimentos dela são só assim, mexe com os braços, mexe as pernas, mas andar, ela não anda." (CP8)

"Ele não anda, não fala, não senta, tem muitos problemas." (CP4)

A fala do cuidador ressalta as dificuldades motoras e verbais dos pacientes. Observa-se também que os níveis de comprometimento diferem um do outro. Algumas crianças são acometidas na fala, apresentam incapacidade motora, como deambular, algumas apresentam atraso no desenvolvimento cognitivo, já outras crianças não necessariamente são acometidas por todas essas limitações. Esses resultados corroboram outro estudo, que identificou que a maior dificuldade das crianças foi a de deambular, pois a maior parte delas sofre com limitações e algumas necessitam, até mesmo, de órteses ou cadeira de $\operatorname{rodas}^{(24,25)}$.

A evolução não satisfatória do quadro clínico do paciente leva à desmotivação por parte do cuidador, tornandose fragilizado pelos aspectos negativos vivenciados. A partir do momento que o cuidador não se sente bem consigo mesmo, torna-se incapaz de manter o foco no cuidado efetivo de qualidade. Assim, estratégias que proporcionem bem-estar são necessárias para que o cuidador esteja apto a oferecer um cuidado com mais qualidade à criança( ${ }^{(26)}$.

\section{Reações do cuidador ao diagnóstico da criança com ECNP}

Nesta categoria, reações cuidador ao diagnóstico da criança com ECNP, destacou-se a dificuldade em meio à negação, aceitação e superação, conforme os trechos abaixo:

"Para mim, foi um pouquinho difícil, que eu não sabia como ajudá-la, mas vieram algumas pessoas e me incentivaram a trazê-la para cá (clínica de Fisioterapia)." (CP3)

"Foi difícil, porque a gente se sente constrangida, a gente se sente rejeitada pela sociedade, principalmente na família, eu... (choro) Quando eu descobri, eu não queria aceitar." (CP2)

"No começo foi horrivel, porque qual é a mãe que aceita ter um filho deficiente, não é? Porque, no começo, quando eu descobri, eu queria... Porque a gente espera, durante aquela gravidez, de ver a criança andando, indo para a escola como as crianças normais, aí, eu não... No começo, eu não queria aceitar, eu queria até me... Fazer aquela besteira... (suicídio), mas com fé em Deus, não é?! A gente enfrenta tudo o que der e vier dos filhos da gente, sendo normal ou não, com fé em Deus a gente enfrenta." (CP5)

Os cuidadores da presente pesquisa relataram não ter conhecimento de como proceder aos cuidados após o diagnóstico. Notou-se um sentimento de impotência e relatos também de sensibilização de terceiros que passaram a dar apoio e incentivo em buscar cuidados especializados. Já outras relataram rejeição pela sociedade e até por membros da família. Algumas referiram extremo desespero frente ao diagnóstico, tendo Deus como uma forma de enfrentar a situação, sendo possível identificar a importância da Clínica de Fisioterapia do Município para o tratamento.

De uma forma geral, as cuidadoras entrevistadas relataram pontos negativos como reações ao diagnóstico. Sabendo que a notícia de que o(a) filho(a) possui ECNP interfere na vida da família e/ou do cuidador, os profissionais de saúde devem contribuir de forma positiva nas relações da criança com os seus familiares/cuidadores, propondo modificações na rotina familiar ${ }^{(27)}$.

A responsabilidade do cuidado, quando é compartilhada em harmonia com outros cuidadores, diminui a jornada de trabalho e, consequentemente, torna-se menos exaustiva, o que pode contribuir positivamente no cuidado e na evolução do paciente ${ }^{(26-28)}$. 
Além disso, duas cuidadoras primárias (CP8 e CP5) relataram que sofreram com a limitação social, pois não conseguem ter uma vida pessoal e muito menos o cuidado geral consigo mesma:

"A minha vida, desde quando ela nasceu, ela tem 21 anos, a minha vida gira em torno dela. Não posso trabalhar, não posso sair para me divertir, muito menos estudar. A minha vida é essa, ficar em casa, cuidar dela." (CP8)

"Vida social eu não tenho, eu só vivo para ela e eu vejo que a minha vida é dela, para ela, tudo assim, sabe? Aí, eu não posso sair, só para resolver as coisas dela e ir à igreja mesmo, e olhe lá, mas eu não sei como vai ser no futuro, porque eu não sei até quando eu vou estar aqui, sabe? Mas, como ela só tem a mim, eu entrego nas mãos de Deus e Ele é quem sabe quem toma de conta, não é?!" (CP5)

Após o diagnóstico, são relatadas alterações no convívio social, devido à necessidade de cuidado constante. Existem relatos de que o enfretamento acontece diferentemente de indivíduo para indivíduo, pois varia de acordo com o modo como a pessoa distingue e enfrenta a realidade, seja na não aceitação, seja na negação relacionada ao diagnóstico ${ }^{(28)}$.

A avaliação do índice da sobrecarga de cuidadores primários de crianças com ECNP mostra que boa parte dos cuidadores se sentem exaustos, devido à responsabilidade total pela criança, limitando alguns dos aspectos da vida desse cuidador, pois acaba abrindo mão de sua vida social para viver apenas a vida dedicada ao(à) filho(a) $)^{(8,28)}$.

\section{Perspectivas futuras da criança com ECNP}

Nesta categoria, perspectivas futuras da criança com ECNP, as cuidadoras desejam a superação da criança em meio à sociedade e autonomia, como se observa nos trechos seguintes:

“Uma mãe sempre pensa o bom para o seu filho... Eu penso nele formado... (risos) em um bom emprego... (risos)... Por que não, não é?!” (CP1)

"Que ela se torne uma pessoa melhor, uma boa pessoa que já é, vencedora e que ela consiga os sonhos dela." (CP3)

"Eu imagino ele um grande homem... (risos) Estudando, fazendo faculdade, ele quer estudar em um curso profissionalizante... Ele sonha muito alto. Ele disse que vai estudar para me ajudar." (CP2)

"Aiii! Eu o imagino como um homem preparado, no mercado, não é?! Ele já está estudando (...) formado, seja o que for, eu o imagino muito bem. Eu não o imagino nem muito doente, assim, dependente, debilitado não. Eu penso nele melhor do que ele está hoje." (CP9)

Embora as cuidadoras entrevistadas, tendo expectativas positivas futuras sobre a criança, ao mesmo tempo apresentavam insegurança quanto ao sucesso, situação atual e diante do prognóstico, referiram perceber características da personalidade da criança como força de vontade e superação. Outras tinham desejo de que a criança chegasse ao ensino superior e se graduasse, mas tinham consciência dos comprometimentos da criança, que dificultariam as realizações desse desejo.

Quanto à inserção da criança na escola, uma das dificuldades é a troca de informação entre aluno, professor, funcionários e, até mesmo, colegas. A falta de conhecimento sobre a doença na escola, a falta de preparo ou de capacitação desses profissionais, pode dificultar o desenvolvimento da criança dependendo do grau de seu desempenho cognitivo e grau de limitação. Outro fator que também pode interferir nesse desenvolvimento é o receio dos pais quanto à rejeição dos colegas ou das pessoas que fazem parte do ambiente, de modo que acabam poupando a criança de algumas situações ou, até mesmo, de algumas atividades, sendo "superprotetores"(25, 29).

\section{Medo de morte da criança portadora de ECNP ou do cuidador}

Sobre esta categoria, medo de morte da criança portadora de ECNP ou do cuidador, as cuidadoras entrevistadas ressaltaram que o maior medo do futuro é chegar a perder o(a) filho(a) ou morrer e deixar a criança só no mundo:

"O que mais me causa medo é ela morrer, perdê-la, e a saúde dela, não é?! O que mais me preocupo é com o bem-estar dela. Ela estando com saúde, para mim é tudo." (CP8)

"O medo é de perdê-la, não é, porque a gente não vive para sempre, pelo resto da vida. Às vezes... eu penso que essas crianças, que têm deficiência, não vivem muito, não têm a vida como nós temos. $E$ esse é o meu grande medo, não gosto nem de pensar, não é?!" (CP5)

"Todo o futuro dele, da parte dele ser um homem feito, sei lá, medo de perder... (pausa longa, voz trêmula e choro compulsivo) Isso eu tenho demais, eu não gosto nem de falar, sabe? Que é o medo que eu mais tenho, porque eu sei que ele não vai me ter toda vida, não é?! Como é que vai ser a vida dele." (CP1) 
Entre as perspectivas futuras, a morte da criança e do próprio cuidador aparece em algumas falas, comprometendo a continuidade do cuidado da criança, tendo como a saúde um ponto primordial para o bem-estar físico e psicológico. Uma das principais preocupações dos familiares de crianças com ECNP é o medo da própria morte, considerando que são os principais cuidadores da criança ou do adulto que, nessas condições, necessitam de cuidados básicos e permanentes para sobreviver. Essa preocupação gera ansiedade e incertezas em relação ao futuro. Além da própria morte, há o receio de vivenciar a morte do filho( ${ }^{(30)}$.

\section{Preconceito com a criança portadora de ECNP}

Nesta categoria, preconceito com a criança portadora de ECNP, destaca-se também que as mães temem como $\mathrm{o}(\mathrm{a})$ filho (a) irá reagir caso algum preconceito venha a surgir no futuro:

"É... Mais na frente, algum preconceito, alguma reação sobre outras pessoas, as rejeições que ela pode enfrentar pela frente, agora não, mas a gente não sabe quando ela passar para outras escolas, não é?! Não sei se vai ter alguma rejeição, não é?! Contra isso... com ela... que eu consiga lidar com isso com ela." (CP 3) "Tenho receio de como as pessoas vão olhar para ele diferente, eu tenho medo, porque principalmente na escola, não é?! Quando ele começar a estudar e observarem que ele é diferente, vê-lo com alguma limitação... Aí, vão querer apontar para ele e vão... tipo excluí-lo... Achar que ele não é normal, é isso que eu acho." (CP7)

Mas as cuidadoras entrevistadas relataram o receio quanto ao ambiente escolar na vida futura da criança. Nas falas nota-se, também, o interesse em enfrentar as adversidades com a criança. Relatam que medo de que, devido às condições físicas serem perceptíveis, ocorra algum tipo de exclusão e esta possa comprometer a autoestima. É sabido que ocorrem também o preconceito e a discriminação, pois, é uma barreira que elas nem sempre conseguem reagir, a esses preconceitos, tornando-as impotentes. Neste estudo, essas barreiras também estiveram presentes, de modo que o medo do futuro devido ao preconceito gera uma preocupação no cuidador primário ${ }^{(28)}$.

\section{A criança portadora de ECNP sobrecarrega a saúde do cuidador}

Entre as dificuldades vividas, esta categoria, a criança portadora de ECNP sobrecarrega a saúde do cuidador, foi bastante mencionada pelas mães, havendo relatos de sobrecarga física, como dor nas costas, nos braços e limitação dos movimentos:

"Eu? Sinto muita dor nas costas, dor na coluna. Às vezes, à noite, eu mal consigo dormir, dor nos braços, dor nas pernas, aí eu faço até caminhada para ver se eu melhoro. A dor na coluna ocorre só de eu estar levantando ela, porque já está com 14 anos, ela está quase do meu tamanho e está muito pesada. Meus pés incham, às vezes, e outra, ela sempre ronca. Tem um ronco muito forte, e eu não consigo dormir direito, e por isso, tenho medo de ela morrer sufocada ou engasgada. Às vezes, me bate o desespero e eu penso até em fazer besteira comigo (suicídio), sabe?" (CP5)

"Assim, eu sinto muita dor nas costas, não é, porque ela já está muito pesada, mas dá para ir levando, não é?! Eu não sei até quando, porque o tempo vai passando. A gente vai perdendo as forças, os movimentos, vão aparecendo as dores e vão piorando, aí não sei como é que vai ser no futuro, não. Eu tenho medo do futuro." (CP8)

Geralmente, a sobrecarga, tanto pelo peso da criança que está em crescimento como pela dedicação excessiva que a criança requer, acarretam problemas de saúde ao cuidador, como depressão, problemas de coluna, exaustão, cansaço físico e mental. Viu-se que, nas entrelinhas, elas mencionam o desejo de cometer suicídio. É sabido que o suicídio é um problema emergente e multidimensional, sendo necessário que os profissionais de saúde ampliem seus conhecimentos sobre o tema e se sensibilizem para prevenir e realizar um manejo adequado da crise suicida, a fim de promover a saúde ${ }^{(31)}$, e também ter uma atenção humanizada com o cuidador.

Sobre as queixas mencionadas pelas cuidadoras, as crianças com ECNP necessitam de auxílio e suporte durante o dia, e isso gera uma sobrecarga no cuidador, podendo causar lombalgia ou outro sintoma musculoesquelético, que pode ocorrer devido às locomoções diárias que o cuidador exerce de acordo com as necessidades da criança ${ }^{(32)}$. Não necessariamente o cuidador apresentará quadros álgicos ou, até mesmo, se sentirá sobrecarregado ao extremo, pelo contrário, existem casos em que estes têm uma sobrecarga moderada devido aos auxílios familiares, que ajudam na responsabilidade diária do filho ${ }^{(31,32)}$.

Os profissionais de saúde devem orientar e incentivar a mãe da criança a torná-la independente dentro de seus próprios limites, esclarecendo-as quanto ao manuseio adequado em casa e à postura utilizada durante a realização 
de atividades diárias, prevenindo uma possível sobrecarga física e problemas posturais, orientações capazes de promover bem-estar ${ }^{(29,32)}$.

Ainda assim, os cuidadores entrevistados relataram "não se sentir sobrecarregados fisicamente", como se pode observar nos trechos abaixo, mas notou-se que esses relatos surgem dos cuidadores das crianças que não têm total dependência, ou seja, cuidadores primários das crianças que não têm uma limitação total. Já outros (CP6 e CP1) citaram que, por mais que dediquem a maior parte do tempo para cuidar dos filhos, não apresentam queixa alguma:

"Não, eu não tenho problema." (CP6)

"Não, eu só me sinto cansada às vezes, porque cansa, mas problema físico, assim, não, até minha mente esclareceu mais, porque... devido ele (criança) ensinar muitas coisas para gente, ele ensina." (CP1)

Apesar da inegável sobrecarga social, física e psicológica que os cuidadores relatam, algumas vezes, isso não é percebido. Possivelmente, pela total entrega ao cuidado, passando a considerar as condições patológicas da criança como naturais ao processo do cuidado. Sugere-se mais estudos sobre os cuidadores de crianças com ECNP, devido à demanda despendida à criança e à carência de autocuidado, que compromete os aspectos físicos e emocionais associados ao cuidado com a criança ${ }^{(4,32)}$. O fisioterapeuta pode auxiliar dando orientações sobre o posicionamento do cuidador ao manejar o paciente, proporcionando melhorias nas queixas de dores musculoesqueléticas ${ }^{(11,32)}$.

Os resultados do presente estudo são semelhantes às outras pesquisas que identificaram que a vida dos cuidadores de pacientes com ECNP é insatisfatória, principalmente no domínio físico e psicológico, já que, desde o nascimento da criança, passaram a viver em função delas, destinando para segundo plano seus sonhos e objetivos, levando-os a se apresentarem frustrados e insatisfeitos com a própria vida ${ }^{(26,27,30)}$.

A tarefa de cuidar é complexa e, muitas vezes, é confiada a indivíduos que não se encontram preparados para desempenhar tal função. Do mesmo modo, é uma atividade permeada por sentimentos diversos e contraditórios, visto a necessidade de realizar funções específicas que, muitas vezes, os cuidadores não estavam preparados para exercer ${ }^{(17)}$, principalmente porque se trata de cuidar de um ente querido, o que envolve emoções.

Tais resultados podem ser aplicados para outras realidades em que haja dependência de cuidados, seja na área da neuropediatria, seja na neurologia adulta. É sabido que a saúde de pessoas dependentes de cuidado é afetada diretamente pela qualidade do cuidado que recebem e, para isto, faz-se necessário o desenvolvimento de espaços para a promoção de empoderamento dos cuidadores, para que possam encontrar redes de apoio em que possam compartilhar medos e dificuldades e sucessos no desempenho de suas funções ${ }^{(19)}$.

A Política Nacional de Promoção da Saúde ${ }^{(16)}$ preconiza o incremento e a ampliação dos serviços de atenção básica, que podem contribuir para a prevenção e promoção à saúde individual e da coletividade. Destaca-se aqui que essa disfunção neuromotora na criança tem impacto na criança, na família, na sociedade e, sobretudo, em quem assume o cuidado da criança desde o nascimento, que normalmente é a mãe. Assim, o conhecimento sobre essa doença deve ser repassado desde o pré-natal, sendo imprescindíveis informações sobre essa doença, a fim de auxiliar em ações preventivas, através da educação em saúde, para as mulheres no período gestacional.

$\mathrm{O}$ atual estudo foi limitado por ter sido realizado em apenas um local de estudo. Sugere-se o desenvolvimento de novos estudos envolvendo cuidadores de pessoas com outras patologias, para que possam identificar seus sentimentos e angústias e, assim, o atendimento voltado a esse público seja valorizado quanto às suas necessidades, sejam físicas, sejam psíquicas, enaltecendo não só o paciente, mas sensibilizando a equipe multidisciplinar e os gestores de saúde para que possam dar uma atenção humanizada a esses cuidadores.

\section{CONSIDERAÇÕES FINAIS}

É de grande valia evidenciar, por meio do olhar do cuidador, o que é cuidar de pacientes com ECNP. Viu-se que eles reagiram negativamente ao diagnóstico da condição de saúde da criança e sentem falta do apoio de amigos e familiares.

Acredita-se que a força de vontade das cuidadoras supera as dores do corpo. É conveniente um olhar diferenciado dos profissionais de saúde e gestores, proporcionando uma atenção humanizada a essas mulheres cuidadoras, que passam por fases críticas desde o nascimento da criança com ECNP. As formas de enfrentamento diferem de uma cuidadora para outra, mas todas necessitam de apoio dos profissionais de saúde para o tratamento e orientações para o cuidado adequado da criança e também para o autocuidado. 


\section{AGRADECIMENTOS}

Os autores agradecem aos gestores de saúde do município, que autorizaram a realização da pesquisa, e às mães cuidadoras participantes da pesquisa.

\section{CONFLITOS DE INTERESSE}

Não houve conflitos de interesses.

\section{CONTRIBUIÇÕES}

Érika Alves Germano e Mara Dayanne Alves Ribeiro contribuíram com a elaboração e delineamento do estudo; a aquisição, análise e interpretação dos dados; e a redação e/ou revisão do manuscrito. Mauro Vinicius Dutra Girão contribuiu com a aquisição, análise e interpretação dos dados; e a redação e revisão do manuscrito. Edna Pinto Medeiros de Lima contribuiu com a aquisição, análise e interpretação dos dados. Maria Dandara Alves Ribeiro contribuiu com a redação e/ou revisão do manuscrito.

\section{REFERÊNCIAS}

1. Pereira HV. Paralisia cerebral. Rev Resid Pediátr. 2018;8(1):49-55.

2. Coelho ACS, Freitas STT, Guimarães CL, Pizzolato TCO. Aspectos clínicos epidemiológicos de crianças com paralisia cerebral assistidas pela clínica escola de Fisioterapia UNIP- São José dos Campos. Jorn Health Sci Inst. 2014;32(3):281-5.

3. Afonso T, Ramos MFH, França IL, Pontes FAR, Silva SSC. Cuidado parental à criança com paralisia cerebral: Uma revisão sistemática da literatura. Rev Bras Ed Esp. 2016;22(3):455-70.

4. Ministério da Saúde (BR), Secretaria de Atenção à Saúde, Departamento de Ações Programáticas Estratégicas. Diretrizes de atenção à pessoa com paralisia cerebral. Brasília: Ministério da Saúde; 2013.

5. Santos AF. Paralisia cerebral: uma revisão da literatura. Montes Claros. 2014;16(2).

6. Casaes CS, Lima IP, Gouvêa D, Abrahão P, Freitas V. Encefalopatia crônica da infância. Ciênc Atual. 2015;5(1):2-7.

7. Vieira JLR, Chagas JRLP. Perfil funcional e sócio demográfico dos pacientes com paralisia cerebral em reabilitação num centro de referência em salvador. Rev Bras Neurol Psiquiatr. 2017;21(2):100-8.

8. Barbosa AM, Correa PFL, Ferreira MC, Gardenghi G, Naccio BL, Otsuka MYC. Avaliação do índice de sobrecarga de cuidadores primários de crianças com paralisia cerebral e sua relação com a qualidade de vida e aspectos socioeconômicos. Rev Acta Fisiatra. 2015;22(1).

9. Santos RM, Massi G, Willig MH, Carnevale LB, Berberian AP, Freire MHS, et al. Crianças e adolescentes com paralisia cerebral na perspectiva de cuidadores familiares. Rev CEFAC. 2017;19(1).

10. Santos KH, Marques D, Souza AC. Crianças e adolescentes com paralisia cerebral: análise sobre Iongitudinalidade do cuidado. Texto \& Contexto Emferm. 2017;26(2).

11. Nohara SS, Bonifácio SR, Ribeiro KT, Lanuez FV, Lemos LC. Atuação fisioterapêutica na sobrecarga física e dor de cuidadores de crianças com paralisia cerebral. Rev Bras Promoç Saúde. 2017;30(4).

12. Boehs AE, Mergner PG, Patel JV, Rocha MDHA, Rocha PFA, Silva AMF. O cuidado da família da criança com paralisia cerebral: Uma revisão integrativa. Rev Enferm. 2016;12(12).

13. Santos TV, Yamada A, Cardoso FM, Ferro FAR, Andrade KF, Gonçalves LFS. Avaliação da sobrecarga imposta a cuidadores primários de pacientes com paralisia cerebral. Rev Amazôn Sci Health. 2017;5(1).

14. Silva SSC, Pontes FAR. Rotina de famílias de crianças com paralisia cerebral. Rev Educar. 2016;59.

15. Lagae L, Irwin J, Gibson E, Battersby A. Caregiver impact and health service use in high and low severity Dravet syndrome: a multinational cohort study. Seizure. 2019;65:72-9. 
16. Ministério da Saúde (BR), Secretaria de Vigilância em Saúde, Secretaria de Atenção à Saúde. Política Nacional de Promoção da Saúde: PNPS: Anexo I da Portaria de Consolidação $n^{\circ} 2$, de 28 de setembro de 2017, que consolida as normas sobre as políticas nacionais de saúde do SUS. Brasília: Ministério da Saúde; 2018.

17. Martins HHTS. Metodologia qualitativa de pesquisa. Rev Educ Pesqui. 2004;30(2):289-300.

18. Saunders M, Lewis P, Thornhill A. Research Methods for Business Students. 6th ed. Harlow: Pearson Education Limited; 2012.

19. Ministério da Saúde (BR). Caderno de Atenção Domiciliar. Brasília: Ministério da Saúde; 2012.

20. Fontanella BJB, Ricas J, Turato ER. Amostragem por saturação em pesquisas qualitativas em saúde: contribuições teóricas. Cad Saúde Pública. 2008;24(1).

21. Manzini EJ. Considerações sobre a elaboração de roteiro para entrevista semi-estruturada. In: Marquezine MC, Almeida MA, Omote S, organizadores. Colóquios sobre pesquisa em Educação Especial. Londrina: eduel; 2003. p.11-25.

22. Bardin L. Análise de conteúdo. Lisboa: Edições 70; 2011.

23. Freitag VL, Lange C, Milbrath VM, Scheider FVM. O impacto do diagnóstico de paralisia cerebral para a família: revisão integrativa. J Nurs Health. 2017;7(1).

24. Monteiro CBM, Abreu LC, Valenti VE. Paralisia cerebral: teoria e prática. São Paulo: Plêiade; 2016.

25. Marques J, Sá L. Limitações motoras e crescimento em crianças com paralisia cerebral motor. Rev Enferm UFPE. 2016;10(1).

26. Berberian AP, Carnevale LB, Carvalho TP, Freire MH, Massi G, Santos RM, et al. Paralisia cerebral na visão de cuidadores familiares. Rev CEFAC. 2017;19(1).

27. Faro A, Nascimento AO. Estratégias de enfrentamento e o sofrimento de mães de filhos com paralisia cerebral. Rev Salud Soc. 2015;3(6).

28. Dantas MAS, Nobrega VM, Fechine CPNS, Torquato IMB, Assis WD, Collet N. Atenção profissional à criança com paralisia cerebral e sua família. Rev Enferm UERJ. 2017;25(esp.).

29. Smeha LN, Abaid JLW, Martins JS, Weber AS, Fontoura NM, Castagna L. Cuidando de um filho com diagnóstico de paralisia cerebral: sentimentos e expectativas. Rev Psicologia em Estudo. 2017;22(2).

30. Guerra HS, Almeida NAM, Souza MR, Minamisava MRS. A Sobrecarga do cuidador domiciliar. Rev Bras Promoç Saúde. 2017;30(2).

31. Teixeira SMO, Souza LEC, Viana LMM. O suicídio como questão de saúde pública. Rev Bras Promoç Saúde. 2018;31(3).

32. Queiroz D, Brito C, Magalhães M, Pereira E, Peres T. Prevalência de lombalgia e incapacidade funcional em cuidadores de crianças e adolescentes com paralisia cerebral. Rev Inspirar Mov Saúde. 2018;15(1).

\author{
Endereço para correspondência: \\ Érika Alves Germano \\ Centro Universitário Instituto Superior de Teologia Aplicada - Uninta \\ Rua Antônio Rodrigues Magalhães, 359 \\ Bairro: Dom Expedito \\ CEP: 62050-100 - Sobral - CE - Brasil \\ E-mail: erikagermanofisio26@gmail.com
}

Como citar: Germano EA, Lima EPM, Girão MVD, Ribeiro MDA, Ribeiro MDA. A criança com encefalopatia crônica não progressiva: impacto da doença para o cuidador. Rev Bras Promoç Saúde. 2021;34:10833. 